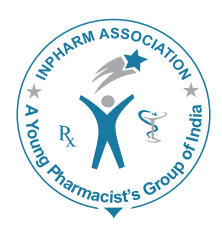

\title{
JIP
}

\section{Black tea extract ameliorates indomethacin induced changes in testicular histopathology of albino rats}

\author{
Ishwar B Bagoji', MA Doshi², Saeed Yendigeri³, BG Patil', BB Patil', \\ Kusal K Das ${ }^{4 *}$
}

\author{
${ }^{1}$ Department of Anatomy, BLDE University's Shri BM Patil Medical College Hospital and Research Centre, \\ Bijapur, Karnataka, India, ${ }^{2}$ Department of Anatomy, Krishna Institute of Medical Sciences University, \\ Karad, Satara, Maharashtra, India, ${ }^{3}$ Department of Pathology, Al Ameen Medical College, Bijapur, \\ Karnataka, India, ${ }^{4}$ Department of Physiology, BLDE University's Shri BM Patil Medical College Hospital \\ and Research Centre, Bijapur, Karnataka, India
}

\begin{abstract}
Context: Reactive oxygen species and lipid peroxidation play a role in the pathogenesis induced by the non-steroidal antiinflammatory drug indomethacin. Aims: This study was aimed to assess the simultaneous effect of black tea extract (BTE) on indomethacin induced alteration in testicular pathology. Materials and Methods: Adult rats were divided into four groups $(n$ = 6/group); Group I (control); Group II (indomethacin, 5 mg/kg b.wt.; i.p.); Group III (BTE, $2.5 \mathrm{~g}$ tea leaf $/ \mathrm{dL}$ of water, i.e., $2.5 \%$ of aqueous BTE, orally) and Group IV (indomethacin + BTE). Serum vitamin E, sperm count, motility, and histopathology of testes were evaluated. Statistical Analysis: Statistical comparisons were performed using the one-way ANOVA, followed by post-hoc t-test. Results: Indomethacin induced rats showed a significant decrease in testicular weight, sperm count, sperm motility, and serum vitamin E concentrations. Histopathology of the testes revealed tortuous seminiferous tubules, loss of spermatogenesis process, marked decrease in the number of interstitial cells of Leydig and been replaced by many foci of congestion, edema, necrosis, and interstitial fibrosis. Rats simultaneously treated with BTE and indomethacin showed improvement of testicular weight, sperm count, sperm motility, and serum vitamin E concentrations when compared to indomethacin alone treated rats. Similarly, histopathology of rats treated simultaneously with indomethacin and BTE showed near normal testicular architecture when compared to indomethacin alone treated rats. Conclusion: The result suggests that BTEs might have potential beneficial effect to combat against indomethacin induced testicular damage in rats.
\end{abstract}

Key words: Black tea extract, indomethacin, testicular damage, vitamin $E$

\begin{tabular}{|c|c|}
\hline \multicolumn{2}{|c|}{ Access this article online } \\
\hline Journal Sponsor & \multirow[b]{2}{*}{$\begin{array}{l}\text { Website: } \\
\text { www.jyoungpharm.org }\end{array}$} \\
\hline \multirow{2}{*}{ www.phcog net } & \\
\hline & $\begin{array}{l}\text { DOI: } \\
\text { 10.5530/jyp.2014.3.9 }\end{array}$ \\
\hline
\end{tabular}

\section{INTRODUCTION}

Non-steroidal anti-inflammatory drugs (NSAIDs) are the most widely used in medication in the world because of its efficacy to reduce pain and inflammation. ${ }^{1}$ Its efficacy has been documented in a number of clinical disorders, including osteoarthritis, rheumatoid, arthritis, ankylosing spondylitis, gout, dysmenorrhea dental pain and headache. ${ }^{2}$

*Address for correspondence:

Prof. Kusal K Das, Department of Physiology, BLDE University's Shri BM Patil Medical College and Research Centre,

Bijapur - 586 103, Karnataka, India.E-mail: kusaldas@yahoo.com 
Indomethacin is a NSAID drug and associated with several side-effect like nausea, vomiting, diarrhea, constipation, decreased apatite, rash, dizziness, headache, drowsiness, and gastric ulcers. There are some reports on indomethacin that it induces detrimental effects on reduction in seminal volume, sperm count, and motility. ${ }^{3}$ Indomethacin leads to mitochondrial oxidative stress associated with the generation of intra-mitochondrial reactive oxygen species (ROS), which induces imbalance of oxidants and antioxidants status in living system. ${ }^{4}$ ROS and lipid peroxidation play a role in the testicular pathogenesis induced by the NSAID like indomethacin. ${ }^{5}$

Black tea extracts (BTE) acts as an effective suppresser of ROS in animals as it is a good source of antioxidants especially flavonoids. Moderate intake of black tea improves the levels of independent risk factors of cardiovascular disease and antioxidant defenses in plasma. ${ }^{6}$

The present study was aimed to assess the protective role of BTE on indomethacin induced alteration of testicular pathogenesis in albino rats.

\section{MATERIALS AND METHODS}

Wister strain of albino male rats aged 50-60 days and 160 $\pm 10 \mathrm{~g}$ body weight was used in this study. All animals were fed with water and food ad libitum. Experiments were carried out after obtaining Institutional Animal Ethical Committee approval. Animal breeding and maintenance were done in accordance with guidelines of Government of India for use of laboratory animals. ${ }^{7}$

\section{Preparation of $2.5 \%$ aqueous BTE}

The black tea (Camellia sinensis) extract was prepared from cut, tear and crush broken orange pickoe grade black clonal tea. It was processed and supplied by Tocklai Experimental Station, Jorthat, Assam. A fresh 2.5\% aqueous BTE was prepared every day following the method of Wei et al..$^{8}$ Twenty-five gram of black tea was added to $500 \mathrm{~mL}$ of boiling water and was steeped for $15 \mathrm{~min}$. The infusion will be cooled to room temperature and then filtered. The tea leaves were extracted a second time with $500 \mathrm{~mL}$ of boiling water and filtered, and the two filtrates were combined to obtain a $2.5 \%$ aqueous BTE $(2.5 \mathrm{~g}$ of tea leaf/100 mL water). The resulting clear solution is similar to tea brews consumed by humans. ${ }^{9}$

The Wister strain male albino rat (150-170 g) were chosen, and animals were divided into four groups, i.e., Group I: Control; Group II: Indomethacin $(5 \mathrm{mg} / \mathrm{kg}$ b.wt.; i.p. for
21 days); ${ }^{10}$ Group III (BTE dose of $2.5 \mathrm{~g}$ tea leaf/dl of water that is $2.5 \%$ of aqueous BTE also for 21 days orally) and Group IV (both indomethacin and BTE simultaneously for 21 days). All the animals were sacrificed at the end of the last dose after an overnight fast. All the experimental procedures followed were performed in accordance with the approval of the Institutional Animal Ethics Committee (1169/ ac/08/CPCSEA) under strict compliance of Committee for the Purpose of Control and Supervision of Experiments on Animals guidelines for the experimental studies.

\section{Gravimetry}

The body weights of all animals were recorded on the $1^{\text {st }}$ day of the indomethacin treatment and the day of sacrifice. The testicular weight was determined after dissecting out, and washing in ice-cold saline in a single-pan balance (ATCO. M. No. D2RS02-W).

\section{Animal sacrifice and serum collection}

At the end of the last dose, the animals were sacrificed after overnight fasting by decapitation between 09.00 AM and 11.30 AM to avert the circadian influences on the animals. ${ }^{11}$ Blood was collected in centrifuge tubes, kept at room temperature for about $2 \mathrm{~h}$ and centrifuged at $1500 \times g$ for 15 min to collect serum.

\section{Vitamin E assay}

Serum was used for the estimations of $\alpha$-tocopherol concentration by the modified method of Jargar et al. ${ }^{12}$

\section{Determination of sperm count and motility}

Both the sperm count and motility was determined by the method of Makler. ${ }^{13}$ Briefly; a sperm count was performed on sperm samples collected from the cauda epididymis. The cauda portion was separated and placed in $0.25 \mathrm{M}$ sucrose solution. The epididymal tubes were punctured with a fine hypodermic needle and spermatozoa were extruded by squeezing. Sperm heads within a $10^{2}$ area were counted in the same manner as blood cells counted in a hemocytometer; their number represents their concentration in millions $/ \mathrm{mL}$.

\section{Histopathological studies}

After sacrifice, testis of the experimental rats were dissected out (of one side) and stored in Bouin's fixative solution and processed. Fixed tissues were cut and stained with hematoxylin and eosin accordingly. ${ }^{14}$ The sections were examined under a light microscope, and photomicrographs 
were taken by using USB MIPS (NO. 70.0343) with a connected personal computer.

\section{Statistical analysis}

Data were expressed as mean \pm standard deviation of the mean. Statistical comparisons were performed by one-way ANOVA, followed by post-hoc $t$-test, and the values were considered as statistically significant when $P<0.05$.

\section{RESULTS}

\section{Gravimetry}

Table 1 shows the lowest percentage of body weight gain in case of Group II (indomethacin) rats. A significant improvement of percentage of body weight gain was observed in the indomethacin treated rats which were supplemented with BTE. Group III (only BTE) rats did not show any significant changes as compared to Group I rats. Similarly, significant decreased of testicular weight were noticed in the case of Group II (indomethacin) rats, but in case of Group IV (BTE + indomethacin) a remarkable improvement in weight of testis were also observed.

\section{Vitamin E Assay}

From Table 2, it may be observed that indomethacin significantly decreases serum vitamin E levels (Group II). However, supplementation of BTE on indomethacin treated rats (Group IV) showed an improvement of the level of serum vitamin E concentrations (Figure 1).

\section{Sperm count and motility}

Table 2 shows indomethacin (Group II) induced a significant decrease in the sperm count and motility of the rat in comparison with their control (Group I). Simultaneous supplementation of BTE with indomethacin in Group IV rats, significantly improved sperm count as well as sperm motility when it compared with Group II rats.

\section{Histopathological studies}

The histological structure of normal untreated rat testis (Group I) showed normal architecture (Figure 2a and b). In Group II (Indomethacin) showed majority of the

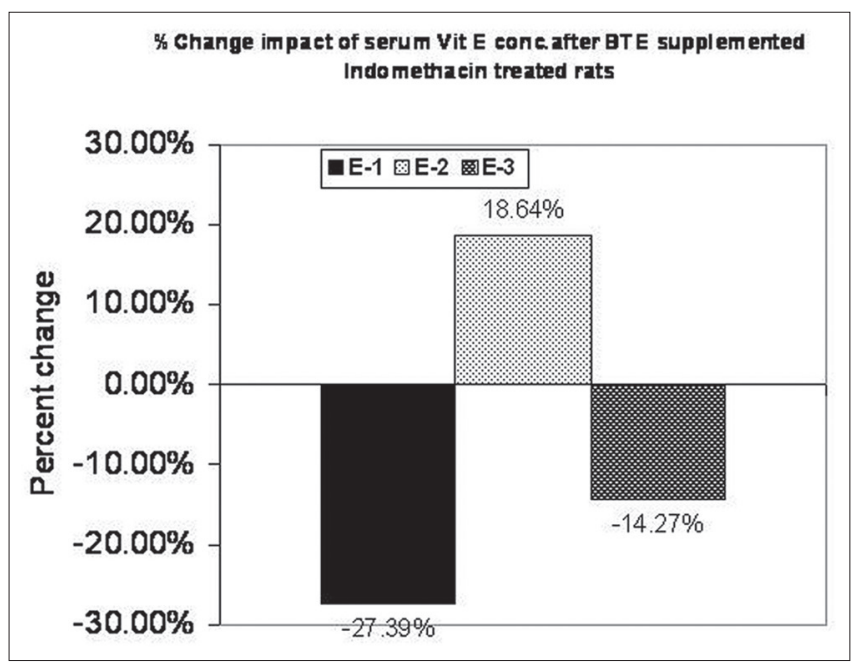

Figure 1: Percentage change of effect of black tea extract on serum vitamin $\mathrm{E}$ concentration in indomethacin treated rats. E-1, Group I versus Group II; E-2, Group I versus Group III; E-3, Group I versus Group IV

Table 1: Effect of BTE (2.5 g tea leaf/dl of water; oral) on gravimetric parameters in male albino rats after indomethacin (NSAID) treatment (5 mg/kg b. wt.; i.p.)

\begin{tabular}{lcccc}
\hline Gravimetry (Grams) & Group I & Group II & Group III & Group IV \\
\hline Initial body weight & $173.50 \pm 12.02^{\mathrm{a}}$ & $168.50 \pm 4.95^{\mathrm{a}}$ & $186.00 \pm 5.66^{\mathrm{a}}$ & $187.50 \pm 10.61^{\mathrm{a}}$ \\
Final body weight & $242.50 \pm 10.61^{\mathrm{a}}$ & $192.50 \pm 3.54^{\mathrm{b}}$ & $254.50 \pm 14.85^{\mathrm{a}}$ & $242.00 \pm 5.66^{\mathrm{a}}$ \\
\% of body weight gain & $39.89 \pm 3.58^{\mathrm{a}}$ & $14.26 \pm 1.26^{\mathrm{b}}$ & $36.77 \pm 3.83^{\mathrm{a}}$ & $29.19 \pm 4.29^{\mathrm{c}}$ \\
Testes & $1.95 \pm 0.1224^{\mathrm{a}}$ & $1.233 \pm 0.1505^{\mathrm{b}}$ & $2.00 \pm 0.6324^{\mathrm{a}}$ & $1.5333 \pm 0.1966^{\mathrm{c}}$ \\
\hline
\end{tabular}

Group I: Control, Group II: Indomethacin treated, Group III: BTE treated, Group IV: BTE + Indomethacin treated. Each value is mean \pm SEM of six observations in each group. In each row, values with different superscripts $(a, b, c, d)$ were significantly different from each other $(P<0.05)$. Post-hoc $t$-test analysis was used to test for differences among the means when ANOVA indicated a significant $P<0.05$. ANOVA: Analysis of variance, BTE: Black tea extract, NSAID: Non-steroidal anti-inflammatory drug

Table 2: Effect of BTE (2.5 g tea leaf/dl of water; oral) and sperm count, motility and biochemical parameter in male albino rats after indomethacin (NSAID) treatment (5 mg/kg b. wt. i.p.)

\begin{tabular}{lcccc}
\hline Test & Group I & Group II & Group III & Group IV \\
\hline Vitamin E $(\mu \mathrm{g} / \mathrm{ml})$ & $15.55 \pm 0.942^{\mathrm{a}}$ & $11.29 \pm 0.47^{\mathrm{b}}$ & $18.45 \pm 0.47^{\mathrm{c}}$ & $13.33 \pm 0.47^{\mathrm{d}}$ \\
Sperm count $(\mathrm{millions} / \mathrm{ml})$ & $53.16+2.23^{\mathrm{a}}$ & $40.83+1.83^{\mathrm{b}}$ & $56.17+1.83^{\mathrm{a}}$ & $45.66+1.63^{\mathrm{c}}$ \\
Sperm motility $(\%)$ & $79.8333+1.1690^{\mathrm{a}}$ & $61.1666+4.4907^{\mathrm{b}}$ & $79.8333+0.7527^{\mathrm{a}}$ & $71.8333+2.4832^{\mathrm{c}}$ \\
\hline
\end{tabular}

Group I: Control, Group II: Indomethacin treated, Group III: BTE treated, Group IV: BTE+Indomethacin treated. Each value is mean \pm SEM of six observations in each group. In each row, values with different superscripts $(a, b, c, d)$ were significantly different from each other $(P<0.05)$. Post-hoc $t$-test analysis was used to test for differences among the means when ANOVA indicated a significant $P<0.05$. ANOVA: Analysis of variance, BTE: Black tea extract, NSAID: Non-steroidal anti-inflammatory drug 

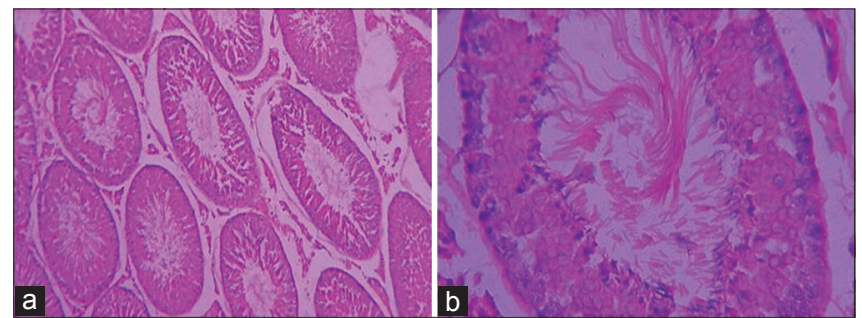

Figure 2: (a) Testis section of normal control Group I ( $\times 10)$, (b) testis section of normal control Group I rats $(\times 45)$

seminiferous tubules appear to be tortuous, marked thickening of tubular basement membrane and germ cell layer, with the loss of spermatogenesis up to $75 \%$. The approximate percentage of spermatogenesis was counted on the basis of concentrations of matured spermatozoa available in the lumen of the seminiferous tubules. Lumen completely filled with sperms was considered as $100 \%$. The fibro vascular stroma present between the seminiferous tubules; showed marked decrease in a number of interstitial cells of Leydig and these were replaced by many foci of congestion, edema, necrosis and interstitial fibrosis (Figure 3a and b). In Group III (BTE) showed normal architecture of histology of testis with spermatocytes, and normal interstitial cells of Leydig (Figure $4 \mathrm{a}$ and b). In Group IV (Indomethacin + BTE) showed a normal testicular parenchymal architecture with seminiferous tubule, and there is mild thickening of tubular basement membrane along with that few foci of loss of spermatogenesis up to $50 \%$ and increase in germ cell layer, with foci of interstitial congestion and edema (Figure 5a and b).

\section{DISCUSSION}

Analgesic and anti-inflammatory compounds have been associated with congenital cryptorchidism in humans, the best-known risk factor for low-semen quality and testicular germ cell cancer. ${ }^{15}$

Table 1 shows the lowest percentage of body weight gain in case of Group II (indomethacin) rats. It indicates that probably indomethacin interfere metabolic pattern of experimental animals. Another possible reason for the least percentage of body weight gain in case of indomethacin treated rats may be due to poor gastro intestinal functions with less absorption of nutrients. The reduction of testicular weight after indomethacin treatment may be also due reduction of protein synthesis or hormonal interferences in testes. ${ }^{16}$ Estimation of serum vitamin $\mathrm{E}$ concentration provides understanding of the circulatory antioxidant status, which facilitates to control the damage to the body from oxidative free radicals. It has been recognized since 1940s that vitamin E

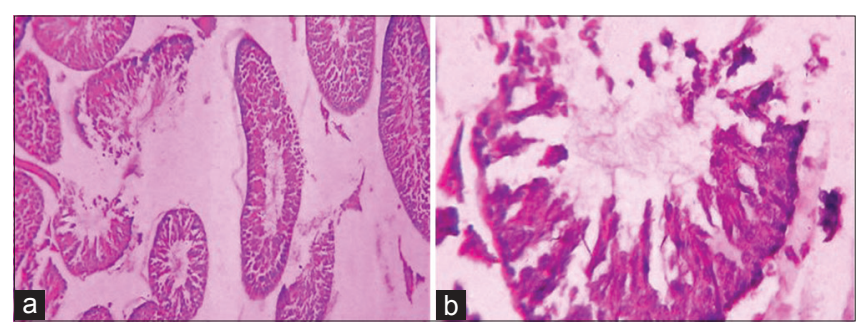

Figure 3: (a) Testis section of indomethacin induced Group II rat $(\times 10)$, (b) testis section of indomethacin induced Group II rat (×45)
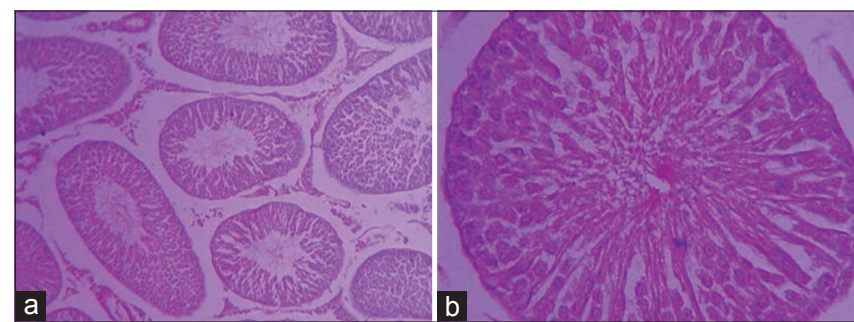

Figure 4: (a) Testis section of black tea extract (BTE) Group III rat (×10), (b) testis section of BTE Group III rat (×45)

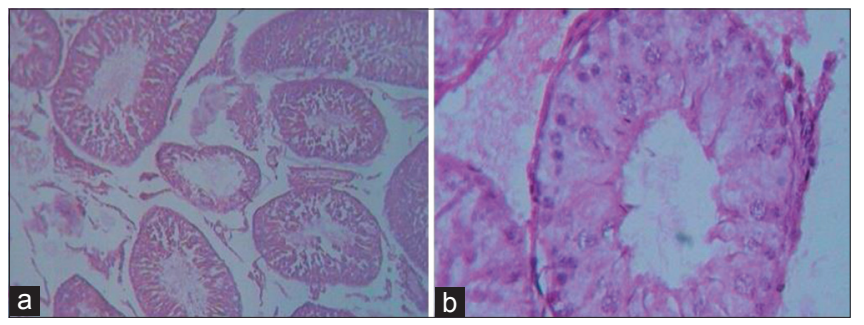

Figure 5: (a) Testis section of black tea extract (BTE) + indomethacin Group IV rat $(\times 10),(b)$ testis section of BTE + indomethacin Group IV rat $(\times 45)$

is a powerful lipophilic antioxidant that is absolutely vital for the maintenance of mammalian spermatogenesis. ${ }^{17}$ In our study, low-serum vitamin E concentration in indomethacin treated rats clearly reflect the adverse effect of indomethacin on antioxidant and prooxidant balance in the blood. ${ }^{18}$ This critical balance between antioxidation/ prooxidation was restored once again after simultaneous treatment of BTEs in the experimental Group IV. Tea flavonoids are potent antioxidants that are absorbed from the gut after consumption. Tea consumption consistently leads to a significant increase in the antioxidant capacity of the blood. Beneficial effects of increased antioxidant capacity in the body may be the reduction of oxidative damage to important biomolecules. ${ }^{19}$ However, the quality of the studies now available is insufficient to draw firm conclusions. In the present study the significant improvement in vitamin E concentration, sperm count and sperm motility and testicular architecture in Group IV rats treated concomitantly with BTE and indomethacin agrees with reports that BTE can be protective against the testicular abnormalities in rats.

Journal of Young Pharmacists Vol 6 • Issue 3 • Jul-Sep 2014 
At the level of the testes, indomethacin induced oxidative stress which may capable of disrupting the steroidogenic capacity of Leydig cells as well as the capacity of the germinal epithelium to differentiate normal spermatozoa. ${ }^{20,21} \mathrm{~A}$ wide variety of different xenobiotic have also been shown to induce oxidative stress in the testes in concert with the suppression of antioxidant mechanisms. Oxidative DNA damage in the male germ line in association with a $32 \%$ reduction in the vitamin $\mathrm{E}$ content of the seminal plasma has already been reported. ${ }^{22}$

In the present study, indomethacin induced decrease sperm count and motility suggests the destruction of the testicular germ cells by membrane damage or macromolecular degeneration. The present study also demonstrated that supplementation of BTE can have positive roles to improve sperm quality via protecting testicular cell membrane and mitochondria.

The results of our histopathological studies indicate that indomethacin probably crossed blood testes barriers and caused degeneration of seminiferous tubules, focal necrosis and decrease spermatogenesis. The change in cellular integrity could be due to the oxidative stress developed by the indomethacin-induced generation of ROS. A significant improvement of testicular architecture in BTEs supplemented indomethacin treated rats clearly indicates ameliorating effects of BTEs.

Hence, it may be concluded that testes are vulnerable to indomethacin but BTEs probably through its antioxidant properties combat against indomethacin induced testicular damage.

\section{ACKNOWLEDGMENT}

Authors acknowledge the financial support from BLDE University, Bijapur to carry out this project.

\section{REFERENCES}

1. Laine L. Approaches to nonsteroidal anti-inflammatory drug use in the high-risk patient. Gastroenterology 2001;120:594-606.

2. Simon LS. Biologic effects of nonsteroidal anti-inflammatory drugs. Curr Opin Rheumatol 1997;9:178-82.
3. Martini AC, Vincenti LM, Santillán ME, Stutz G, Kaplan R, Ruiz RD, et al. Chronic administration of nonsteroidal-antiinflammatory drugs (NSAIDS): Effects upon mouse reproductive functions. Rev Fac Cien Med Univ Nac Cordoba 2008;65:47-59.

4. Takeuchi Y, Morii H, Tamura M, Hayaishi O, Watanabe Y. A possible mechanism of mitochondrial dysfunction during cerebral ischemia: Inhibition of mitochondrial respiration activity by arachidonic acid. Arch Biochem Biophys 1991;289:33-8.

5. Hemieda FA. Melatonin produced metabolic changes in testis and did not prevent indomethacin-induced testicular lipid peroxidation in adult rat. Indian J Exp Biol 2003;41:220-4.

6. Bahorun T, Luximon-Ramma A, Neergheen-Bhujun VS, Gunness TK, Googoolye K, Auger C, et al. The effect of black tea on risk factors of cardiovascular disease in a normal population. Prev Med 2012;54:S98-102.

7. World Medical Organization. Declaration of Helsinki. Br Med J 1996;313:1448-9.

8. Wei H, Zhang X, Zhao JF, Wang ZY, Bickers D, Lebwohl M. Scavenging of hydrogen peroxide and inhibition of ultraviolet light-induced oxidative DNA damage by aqueous extracts from green and black teas. Free Radic Biol Med 1999;26:1427-35.

9. Bartis CA, Ashwood E. Specimen collection and other pre-analytical variables. In: Text Book of Clinical Chemistry. $3^{\text {rd }}$ ed. Philadelphia, Pennsylvania, USA: WB Saunders Co.; 1999. p. 840-1.

10. Owoyele BV, Negedu MN, Olaniran SO, Onasanwo SA, Oguntoye SO, Sanya JO, et al. Analgesic and anti-inflammatory effects of aqueous extract of Zea mays husk in male Wistar rats. J Med Food 2010;13:343-7.

11. Venkataraman BV, Joseph T, Shetty PS, Stephen PM. Acetylcholine levels of rat brain and heart in starvation and protein restriction. Indian J Physiol Pharmacol 1984;28:223-6.

12. Jargar JG, Hattiwale SH, Das S, Dhundasi SA, Das KK. A modified simple method for determination of serum $\alpha$-tocopherol (vitamin E). J Basic Clin Physiol Pharmacol 2012;23:45-8.

13. Makler A. The improved ten-micrometer chamber for rapid sperm count and motility evaluation. Fertil Steril 1980;33:337-8.

14. Culling CF, Ellison RT, Barr W'T. Cellular Pathology Techniques. $4^{\text {th }}$ ed. London: Butterworth and Co.; 1985.

15. Kristensen DM, Lesné L, Le Fol V, Desdoits-Lethimonier C, DejucqRainsford N, Leffers $\mathrm{H}$, et al. Paracetamol (acetaminophen), aspirin (acetylsalicylic acid) and indomethacin are anti-androgenic in the rat foetal testis. Int J Androl 2012;35:377-84.

16. Al-Hamood MH, Elbetieha A, Bataineh $\mathrm{H}$. Sexual maturation and fertility of male and female mice exposed prenatally and postnatally to trivalent and hexavalent chromium compounds. Reprod Fertil Dev 1998;10:179-83.

17. Johnson FC. The antioxidant vitamins. CRC Crit Rev Food Sci Nutr 1979;11:217-309.

18. Das KK, Gupta AD, Dhundasi SA, Patil AM, Das SN, Ambekar JG. Effect of L-ascorbic acid on nickel-induced alterations in serum lipid profiles and liver histopathology in rats. J Basic Clin Physiol Pharmacol 2006;17:29-44.

19. Rietveld A, Wiseman S. Antioxidant effects of tea: Evidence from human clinical trials. J Nutr 2003;133:3285S-92S.

20. Hales DB, Allen JA, Shankara T, Janus P, Buck S, Diemer T, et al. Mitochondrial function in leydig cell steroidogenesis. Ann N Y Acad Sci 2005;1061:120-34.

21. Naughton CK, Nangia AK, Agarwal A. Pathophysiology of varicoceles in male infertility. Hum Reprod Update 2001;7:473-81.

22. Fraga CG, Motchnik PA, Wyrobek AJ, Rempel DM, Ames BN. Smoking and low antioxidant levels increase oxidative damage to sperm DNA. Mutat Res 1996;351:199-203. 